\title{
Iron Calcium Carbonate Instability: Structural Modification of Siderite Corrosion Films
}

\author{
Adriana Matamoros-Veloza,* Richard Barker, Silvia Vargas, and Anne Neville \\ Cite This: ACS Appl. Mater. Interfaces 2020, 12, 49237-49244 \\ Read Online
}

ABSTRACT: Corrosion research related to $\mathrm{CO}_{2}$-containing environments has focused over the past few decades on siderite formation $\left(\mathrm{FeCO}_{3}\right)$ as a main corrosion product on carbon steel, yet the influence of $\mathrm{Ca}$ and other ions on its chemical and structural characteristics is not fully understood. Metal-localized corrosion is the biggest industrial challenge because of the unknown and unpredictable character of this phenomenon that frequently leads to failure. We report here the role of $\mathrm{Ca}$ and formation of iron-calcium carbonate $\left(\mathrm{Fe}_{x} \mathrm{Ca}_{y} \mathrm{CO}_{3}\right)$ through a spiral growth model as in the calcite system and quantify the replacement of $\mathrm{Fe}^{2+}$ by $\mathrm{Ca}^{2+}$ ions

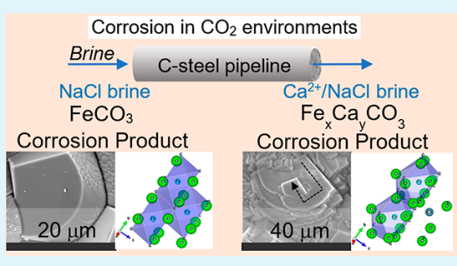
in the structure of $\mathrm{FeCO}_{3}$ to form $\mathrm{Fe}_{x} \mathrm{Ca}_{y} \mathrm{CO}_{3}$. The incorporation of $\mathrm{Ca}^{2+}$ inhibits the completion of spiral segments on the growth of the rhombohedral crystals of $\mathrm{FeCO}_{3}$, promoting an enlargement of its structure along the $c$-axis. This leads to distortions in the chemical structure and morphology affecting the chemical and mechanical properties. Under flow conditions over time in an undersaturated environment, $\mathrm{Ca}$ is leached out from the expanded structure of $\mathrm{Fe}_{x} \mathrm{Ca}_{y} \mathrm{CO}_{3}$ increasing the solubility of the crystals, weakening the mechanical properties of the resulting corrosion films and stimulating localized corrosion.

KEYWORDS: corrosion, siderite, $\mathrm{Fe}_{x} \mathrm{Ca}_{y} \mathrm{CO}_{3}$, iron carbonate, iron calcium carbonate

\section{INTRODUCTION}

Many industries use carbon steel (C-steel) for the construction of pipes, tanks, and pumps for transportation and distribution of bulk gas and liquids demanding an annual steel production of 1.8 billion tonnes. ${ }^{1}$ The major safety and costly problem for industries using C-steel is because of corrosion costing not only lives but capital up to a total of US $\$ 2.5$ trillion per year globally. ${ }^{1,2}$ In oil and gas transport pipelines, corrosion is produced by the chemical interaction between the fluids (i.e., $\mathrm{CO}_{2}$-saturated brine, hydrocarbons, and chemicals) and steel but similar problems are faced in $\mathrm{CO}_{2}$ storage and transport industries. ${ }^{3}$ General corrosion progressively degrades steel materials but the higher risk for pipeline failure is localized corrosion.

Most of the experimental studies regarding corrosion in $\mathrm{CO}_{2}$ environments point out siderite $\left(\mathrm{FeCO}_{3}\right)$ as the main corrosion product although other $\mathrm{Fe}$ oxides coexist. ${ }^{4,5}$ The focus on $\mathrm{FeCO}_{3}$ is in part because of the fact that the majority of the studies aim to investigate the formation of this product alone but in most of the cases it seems that the purpose is to simplify the system. Real applications have more complex chemistries with the presence of other ions (e.g., $\mathrm{Mg}, \mathrm{K}, \mathrm{Ba}$, and $\mathrm{Sr}$ ) in the fluids that cannot only modify the corrosion products but also change the pathway of the reactions, the mechanisms, and kinetics associated. Calcium as an additional ion $\left(\mathrm{Ca}^{2+}\right)$ in the brine solution has been marginally studied in the corrosion field with only a few works published. These works lack of consensus regarding the effect of calcium on corrosion rates. For example, some authors have reported the increase of corrosion rates when $\mathrm{Ca}^{2+}$ is present, ${ }^{6-8}$ while others have documented reduction instead. ${ }^{9,10}$ These discrepancies can be because of the use of different experimental conditions and lack of detail or control of them in the experiments.

Nevertheless, most of these works consistently agree in three main points. First, the presence of $\mathrm{Ca}^{2+}$ leads to the formation of an iron calcium carbonate $\left(\mathrm{Fe}_{x} \mathrm{Ca}_{y} \mathrm{CO}_{3}\right)$ with different morphology and crystallinity in comparison to the extensively studied $\mathrm{FeCO}_{3}$ crystals. ${ }^{8-12}$ Second, the solubility of the asformed $\mathrm{Fe}_{x} \mathrm{Ca}_{y} \mathrm{CO}_{3}$ film increases when compared to a film composed of pure $\mathrm{FeCO}_{3}$ crystals and it has been suggested that this increase relates to a greater porosity of the $\mathrm{Fe}_{x} \mathrm{Ca}_{y} \mathrm{CO}_{3}$ film. ${ }^{11-14}$ Third, localized corrosion has often been observed when the brine solution contains $\mathrm{Ca}^{2+} ;^{7,8,10,13,15,16}$ however, some authors have attributed this effect to the migration of $\mathrm{Cl}^{-}$ through the porous film. ${ }^{15,16}$ Overall, these common observations indicate that the presence of $\mathrm{Ca}^{2+}$ induces changes in siderite crystals, which in turn modify the characteristics of the corrosion films, and their further role in steel degradation.

Received: August 13, 2020

Accepted: September 30, 2020

Published: October 14, 2020 
Furthermore, despite siderite being the most studied corrosion product, the habit (external shape) has just recently described to adopt a rhombohedral geometry comprising of a microfaceted cylinder with trigonal-pyramidal caps. ${ }^{17}$ It is well known that habits can change depending on growth conditions and kinetics, leading to specific growth of crystal faces that exhibit different surface chemistries, and hence different interaction with the fluids. ${ }^{18,19}$ Now, we know that introducing $\mathrm{Ca}^{2+}$ into the growth of siderite produces different morphologies, but we do not know whether the only change is the habit or if structural changes are also taking place. Therefore, this work aims to elucidate and quantify the effects of $\mathrm{Ca}^{2+}$ in the structure of siderite to form an iron calcium carbonate $\left(\mathrm{Fe}_{x} \mathrm{Ca}_{y} \mathrm{CO}_{3}\right)$ corrosion product using molecular approaches. We also investigate the behavior of films formed with this product under reference operating conditions to evaluate their role in the conservation of the underlying steel.

\section{RESULTS AND DISCUSSION}

Initial observations of the crystals grown on C-steel in brine solutions containing $\mathrm{Ca}^{2+}$ showed a rounded morphology in comparison to $\mathrm{FeCO}_{3}$ crystals and evidenced a growth mode in kink sites along steps as reported to occur in calcite (Figure 1). The morphology of these crystals resembles a distorted version of the of $\mathrm{FeCO}_{3}$ morphology. ${ }^{20-22}$ They have rough and smooth surfaces in different directions indicating large anisotropy in bonding. This also suggests that different rates of growth occurred in each direction when compared to siderite, in which smooth crystal faces grow at a slower rate than kinked

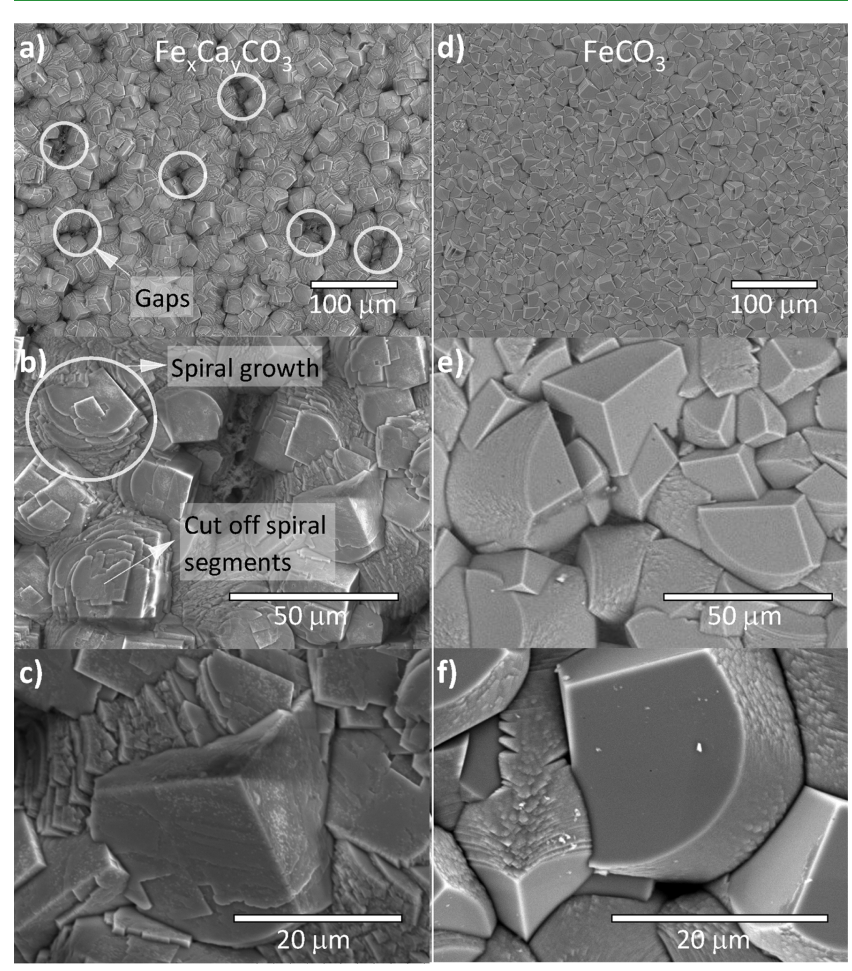

Figure 1. $(\mathrm{a}-\mathrm{c}) \mathrm{SEM}$ images of $\mathrm{Fe}_{x} \mathrm{Ca}_{y} \mathrm{CO}_{3}$ at various magnifications. (a) $\mathrm{Fe}_{x} \mathrm{Ca}_{y} \mathrm{CO}_{3}$ rounded crystals showing gaps between them; (b) details of spiral crystal growth of $\mathrm{Fe}_{x} \mathrm{Ca}_{y} \mathrm{CO}_{3}$ in kink sites along steps and showing the development of a new spiral segment. ${ }^{20}$ (c) Details of $\mathrm{Fe}_{x} \mathrm{Ca}_{y} \mathrm{CO}_{3}$ crystals showing rough and smooth surfaces, and large anisotropy; (d-f) SEM images of $\mathrm{FeCO}_{3}$ grown under identical conditions in the absence of $\mathrm{Ca}^{2+}$. faces (Figure 1). ${ }^{23}$ Figure $1 \mathrm{~b}$ shows that the growth of $\mathrm{Fe}_{x} \mathrm{Ca}_{y} \mathrm{CO}_{3}$ crystals occurred in spiral dislocations similar to the growth of calcite. ${ }^{20}$ The circle in this figure points at the development of a new spiral segment while the arrow shows that the spiral has been cut off. This was observed in various crystals as presented in Figure S1. The presence of $\mathrm{Ca}^{2+}$ induces distortions in the normal rhombohedral geometry of $\mathrm{FeCO}_{3}$, enlarging the step along the $c$-axis and changing its normal progression. This likely increases the formation rate resulting in a disorganized geometry. Certainly, the step enlargement is because of the replacement of $\mathrm{Fe}^{2+}$ with an ionic radii of $0.92 \AA$ by $\mathrm{Ca}^{2+}$ with that of $1.14 \AA$, which is the opposite phenomenon when $\mathrm{Fe}^{2+}$ is incorporated as an impurity in the structure of calcite. ${ }^{24}$ In comparison to the growth of siderite, the incorporation of $\mathrm{Ca}$ in the structure does not allow the normal progression of the steps as the segments forming the spiral in $\mathrm{Fe}_{x} \mathrm{Ca}_{y} \mathrm{CO}_{3}$ have been cut off indicating an inhibition effect (Figure $1 \mathrm{~b}$ ). As expected, this new faster growth geometry introduces stacking faults, strain, and influences the crystal packing, affecting also their arrangement to form a film. This negative effect was evidenced in the inefficient packing of the new formed crystals with gaps between them exposing the bare steel (Figure 1a). Indeed, all these changes have further implications in the chemical (dissolution) and mechanical properties of the iron calcium carbonate and in the developed film. ${ }^{25}$

Diffraction data from the $\mathrm{Fe}_{x} \mathrm{Ca}_{y} \mathrm{CO}_{3}$ corrosion film showed a shift in the peaks to lower $2 \theta$ degrees in comparison to that of $\mathrm{FeCO}_{3}$. For example, the 104 peak of $\mathrm{Fe}_{x} \mathrm{Ca}_{y} \mathrm{CO}_{3}$ shifted to $31.622 \theta$ in comparison to $32.042 \theta$ of $\mathrm{FeCO}_{3}$ confirming a modification of the lattice parameters of pure $\mathrm{FeCO}_{3}$ when $\mathrm{Ca}^{2+}$ replaces $\mathrm{Fe}^{2+}$ in the structure (Figure 2a,b). Calculations yielded an atomic composition of $\mathrm{Fe}_{0.66} \mathrm{Ca}_{0.33} \mathrm{CO}_{3}$ using the equation for a hexagonal lattice that defines the rhombohedral crystal structure of $\mathrm{FeCO}_{3}$, and also using the unit cell volume in combination to the linear equation that relates volume to a mole fraction of $\mathrm{Ca}^{2+}$ as previously reported. ${ }^{7,10}$ Furthermore, diffraction peaks of $\mathrm{Fe}_{0.66} \mathrm{Ca}_{0.33} \mathrm{CO}_{3}$ are noticeably broader than those of siderite resulting from the lattice distortions and dislocations in the crystal structure induced by the incorporation of $\mathrm{Ca}^{2+}$.

To further understand the changes in the structure of siderite when $\mathrm{Ca}^{2+}$ is present, we quantified the geometrical changes in the structure of $\mathrm{Fe}_{0.66} \mathrm{Ca}_{0.33} \mathrm{CO}_{3}$ compared to $\mathrm{FeCO}_{3}$ through XANES analyses. As previously reported, the Fe K-edge XANES spectra of $\mathrm{FeCO}_{3}$ corrosion films, grown under the same conditions of iron calcium carbonate films, have a fingerprint consisting of three peaks between 7110 and $7140 \mathrm{eV}$ as observed in Figure 2c. ${ }^{4,27,28}$ Although both spectra are very similar, there are clear differences in the pre-edge and in the feature after the white line (peak 3) (Figure 2c). For $\mathrm{Fe}_{0.66} \mathrm{Ca}_{0.33} \mathrm{CO}_{3}$, the pre-edge (1s-3d) is a flattened curve in comparison to that of $\mathrm{FeCO}_{3}$. Taking into account that the shape and the centroid of this feature is sensitive to the oxidation state and coordination environment, ${ }^{28,29}$ our results indicate that $\mathrm{Fe}$ as the absorber atom in $\mathrm{Fe}_{0.66} \mathrm{Ca}_{0.33} \mathrm{CO}_{3}$ has a different local chemistry of $\mathrm{Fe}$ (e.g., neighbors and distances) than $\mathrm{Fe}$ in $\mathrm{FeCO}_{3}$. We observed similar results from a region of interest (ROI) of a XANES map corresponding to a cross section of a $\mathrm{Fe}_{0.66} \mathrm{Ca}_{0.33} \mathrm{CO}_{3}$ film (Figures $3 \mathrm{a}-\mathrm{d}$ ). Also, three $\mathrm{Fe}$ environments were identified on the cross section, I, II, and III regions (Figures $3 a-c)$. Spectra I and III represent the chemical environment of $\mathrm{Fe}$ in the steel, while spectrum II 

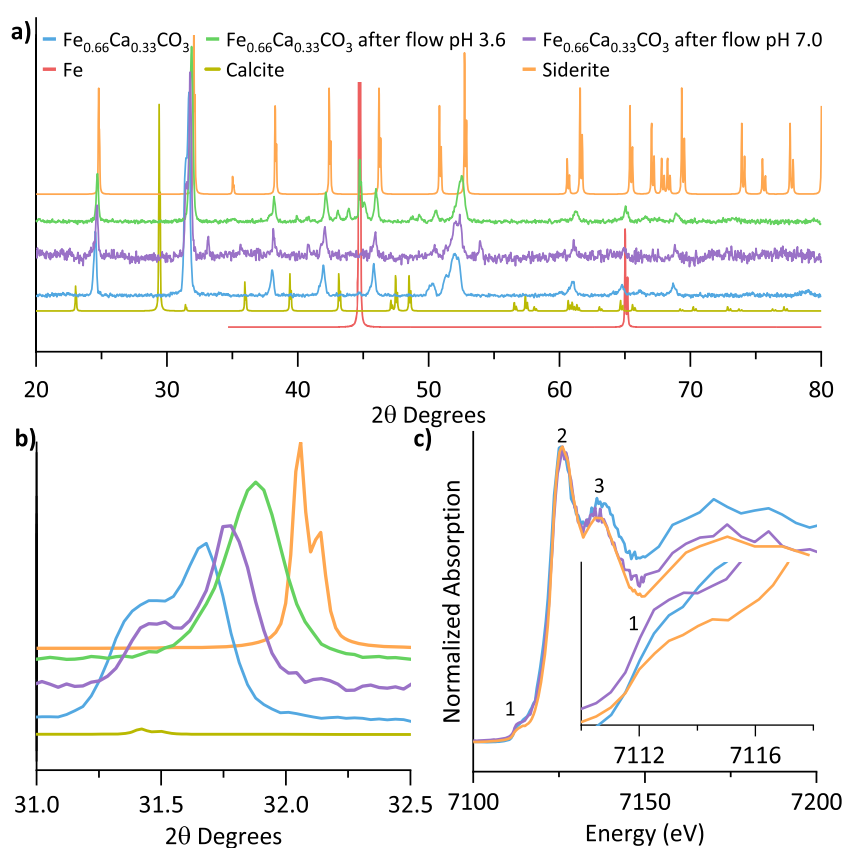

Figure 2. (a) Diffraction patterns collected from $\mathrm{Fe}_{0.66} \mathrm{Ca}_{0.33} \mathrm{CO}_{3}$ corrosion films (initial and after flow experiments) compared to diffractograms of mineral references of the ICDD (Fe 6-0696, siderite 8-0133 and calcite 5-0586); (b) details of the 104 diffraction peak of $\mathrm{FeCO}_{3}$ and $\mathrm{Fe}_{0.66} \mathrm{Ca}_{0.33} \mathrm{CO}_{3}$ (initial and after flow experiments); (c) Fe K-edge XANES spectra of $\mathrm{FeCO}_{3}$ and $\mathrm{Fe}_{0.66} \mathrm{Ca}_{0.33} \mathrm{CO}_{3}$ (initial and after flow experiments) showing three main features (peaks 1-3). The spectra of $\mathrm{FeCO}_{3}$ and $\mathrm{Fe}_{0.66} \mathrm{Ca}_{0.33} \mathrm{CO}_{3}$ after $24 \mathrm{~h}$ flow are remarkably similar but differences in the pre-edge are evident (inset).
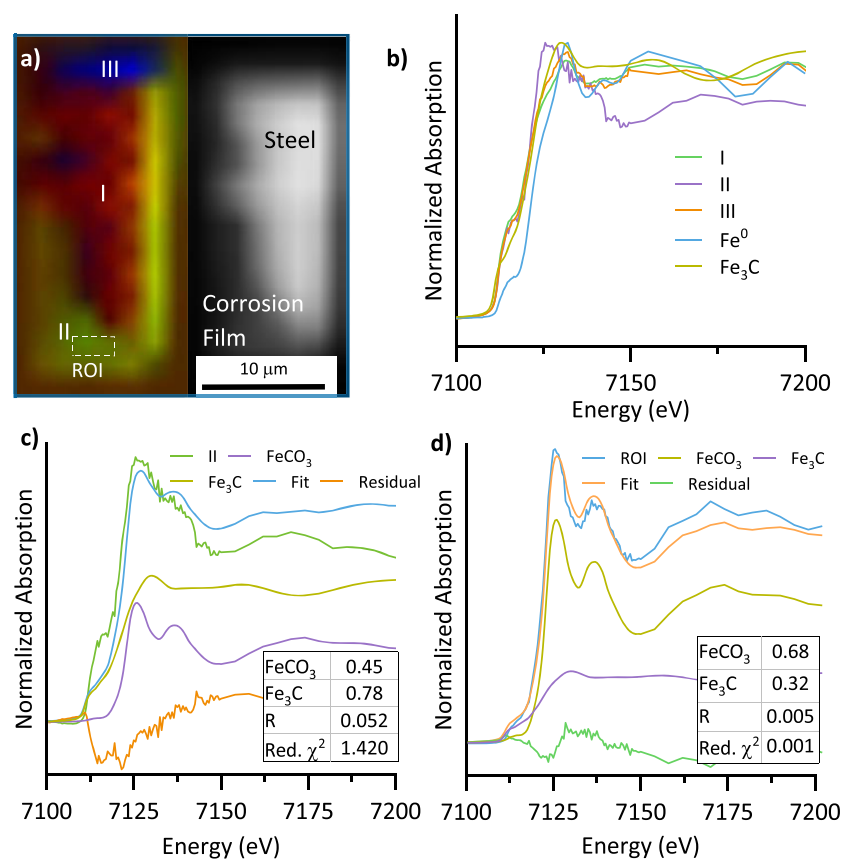

Figure 3. (a) Fe K-edge XANES map $(10 \mu \mathrm{m} \times 20 \mu \mathrm{m})$ from a cross section of the $\mathrm{Fe}_{0.66} \mathrm{Ca}_{0.33} \mathrm{CO}_{3}$ corrosion film $\left(\mathrm{pH} \mathrm{7.0,80}{ }^{\circ} \mathrm{C}\right.$ ) and the corresponding optical microscopy image; (b) Fe K-edge XANES spectra from the three $\mathrm{Fe}$ environments found on the cross section; (c) LCF of the cluster II (film) spectrum along with LCF parameters; (d) Fe K-edge XANES spectrum of a ROI representing the corrosion product. represents a combination of the fingerprints for the $\mathrm{FeCO}_{3}$ and $\mathrm{Fe}_{3} \mathrm{C}$ spectra. However, all the spectra showed clear alteration in the Fe site symmetry (pre-edge) with respect to the spectra of pure siderite and cementite (Figure $3 \mathrm{~b}, \mathrm{~d}$ ).

To investigate further the structural changes in the local environment of $\mathrm{Fe}$ in the $\mathrm{Fe}_{0.66} \mathrm{Ca}_{0.33} \mathrm{CO}_{3}$ crystals, we quantified interatomic distances of $\mathrm{Fe}$ in the structure compared to siderite through extended XAS fine structure (EXAFS) analyses. Initial comparison of the EXAFS data between $\mathrm{Fe}_{0.66} \mathrm{Ca}_{0.33} \mathrm{CO}_{3}$ and $\mathrm{FeCO}_{3}$ obtained from their respective films showed out-of-phase oscillations in $k$-space above $5 \AA^{-1}$ pointing out that $\mathrm{Fe}_{0.66} \mathrm{Ca}_{0.33} \mathrm{CO}_{3}$ and $\mathrm{FeCO}_{3}$ consist of two different structures (Figure 3 ). Such differences were quantified through the comparison of $\mathrm{Fe}-\mathrm{Fe}$ interatomic distances in both $\mathrm{Fe}_{0.66} \mathrm{Ca}_{0.33} \mathrm{CO}_{3}$ and $\mathrm{FeCO}_{3}$ with the theoretical model of siderite. Our EXAFS data from these two types of films were collected in a small $k$-space range (3.0$7.0 \AA^{-1}$ ) and have some amount of noise; however, in our case these data are useful to provide a good estimation of the changes in the distances between $\mathrm{Fe}$ and neighboring atoms as they are not affected by noise in the data. First, we obtained a reasonable fit for the $\mathrm{FeCO}_{3}$ data collected from a film grown using the same conditions for $\mathrm{Fe}_{0.66} \mathrm{Ca}_{0.33} \mathrm{CO}_{3}$ growth (Table $\mathrm{S} 1)$. The fit was achieved with a reduced $\chi^{2}=28$ and an $R$ factor of 0.03 despite the limitations of our data (Figure $4 a-c$ ). $\Delta R$ and $\Delta E_{0}$ were below $0.1 \AA$ and $10 \mathrm{eV}$, respectively, and $\sigma^{2}$ were within expected values $\left(0.003-0.020 \AA^{2}\right)$. Interatomic distances for $\mathrm{Fe}-\mathrm{O}_{1}$ of $2.13 \AA$, $\mathrm{Fe}-\mathrm{C}$ of $3.06 \AA$, $\mathrm{Fe}-\mathrm{O}_{2}$ of 3.24

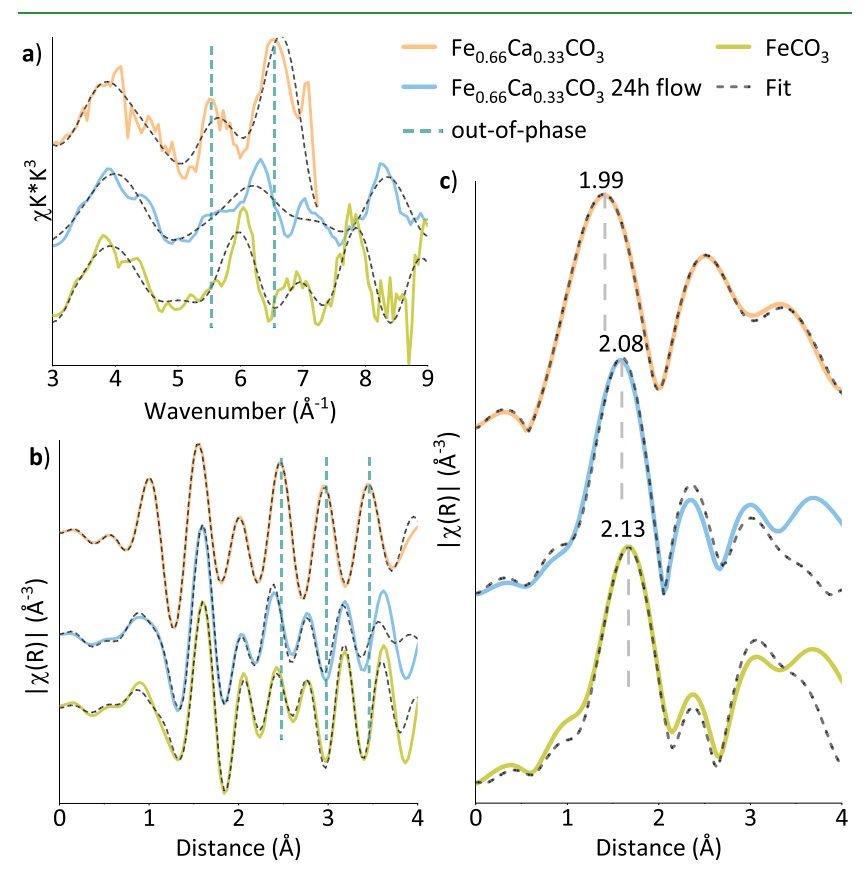

Figure 4. EXAFS fits for data collected from $\mathrm{Fe}_{0.66} \mathrm{Ca}_{0.33} \mathrm{CO}_{3}$ (initial and after $24 \mathrm{~h}$ flow) and $\mathrm{FeCO}_{3}$. (a) $\chi(k)^{*} k^{3}$ of the $\mathrm{Fe}_{0.66} \mathrm{Ca}_{0.33} \mathrm{CO}_{3}$ (initial and after $24 \mathrm{~h}$ flow) and $\mathrm{FeCO}_{3}$ EXAFS experimental data; (b) magnitude and (c) real parts of the Fourier transform of $\chi(k)^{*} k^{3}$. Fits can be seen in Table S1. EXAFS data for the initial $\mathrm{Fe}_{0.66} \mathrm{Ca}_{0.33} \mathrm{CO}_{3}$ is out-of-phase with respect to $\mathrm{FeCO}_{3}$ and $\mathrm{Fe}_{0.66} \mathrm{Ca}_{0.33} \mathrm{CO}_{3}$ after flow, which are themselves in phase evidencing that the initial $\mathrm{Fe}_{0.66} \mathrm{Ca}_{0.33} \mathrm{CO}_{3}$ corrosion product has a different chemical structure with respect to siderite but after flow the atomic arrangement is similar to siderite. Interatomic distances are being affected by the incorporation of $\mathrm{Ca}$ in the structure (i.e., $\mathrm{Fe}-\mathrm{O}$ of $1.99 \AA$ in $\mathrm{Fe}_{0.66} \mathrm{Ca}_{0.33} \mathrm{CO}_{3}$ is shorter than $2.13 \AA$ in siderite). 
$\AA$, and $\mathrm{Fe}-\mathrm{Fe}_{1}$ of $3.70 \AA$ in the $\mathrm{FeCO}_{3}$ crystals were in good agreement with the reported data $\left(\mathrm{Fe}-\mathrm{O}_{1}=2.14 \AA\right.$, $\mathrm{Fe}-\mathrm{C}=$ $3.00 \AA, \mathrm{Fe}-\mathrm{O}_{2}=3.26 \AA$, and $\mathrm{Fe}-\mathrm{Fe}_{1}=3.73 \AA$ for siderite) ${ }^{30}$

Using a $k$-space range between 3.0 and $7.0 \AA^{-1}$, we achieved a consistent fit for the $\mathrm{Fe}_{0.66} \mathrm{Ca}_{0.33} \mathrm{CO}_{3}$ data using the siderite model but created with a substitution of two Fe positions by Ca (Table S1). Fitting values for $\Delta R, \Delta E_{0}$, and $\sigma^{2}$ were satisfactory with $\chi^{2}=35$ and an $R$-factor of 0.05 (Figure $4 \mathrm{a}-\mathrm{c}$ ). Changes in the interatomic distances with respect to siderite (in brackets) were evident, for $\mathrm{Fe}-\mathrm{O}_{1}$ of $1.99 \AA$ ( $2.13 \AA$ ) , Fe$\mathrm{O}_{2}$ of $3.32 \AA(3.26 \AA)$, and $\mathrm{Fe}-\mathrm{Fe}_{1}$ of $3.80 \AA(3.70 \AA)$ confirming the bonding distortion identified with our XANES, scanning electron microscopy (SEM), and X-ray diffraction (XRD) data. Figure 5a,b illustrates how these distortions in
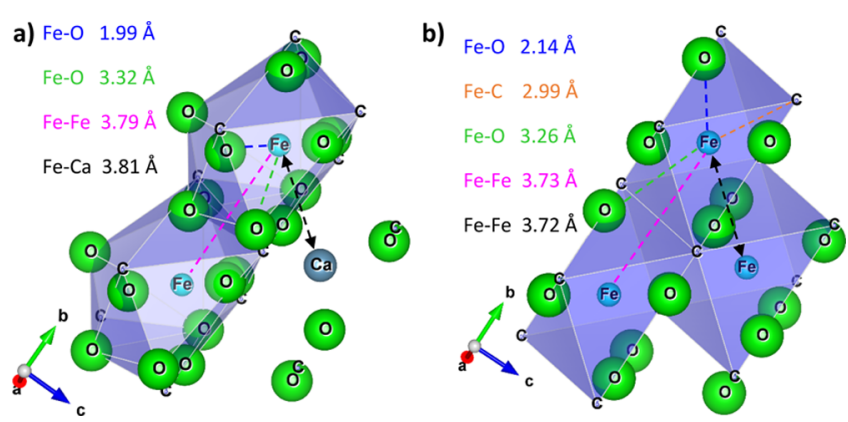

Figure 5. (a) Structure of $\mathrm{Fe}_{x} \mathrm{Ca}_{y} \mathrm{CO}_{3}$ showing the modifications when $\mathrm{Ca}$ replaces $\mathrm{Fe}$ in the structure of $\mathrm{FeCO}_{3}$. It also shows the interatomic distances found in the EXAFS data for $\mathrm{Fe}_{0.66} \mathrm{Ca}_{0.33} \mathrm{CO}_{3}$. Atom sizes are represented as ionic radius. These structures show the increase in the interatomic distance of $\mathrm{Fe}-\mathrm{Ca}(3.81 \AA)$ in $\mathrm{Fe}_{0.66} \mathrm{Ca}_{0.33} \mathrm{CO}_{3}$ compared to $\mathrm{Fe}-\mathrm{Fe}(3.79 \AA)$ in $\mathrm{FeCO}_{3}$ enlarging the structure along the $c$-axis; (b) structure of $\mathrm{FeCO}_{3}$ showing the interatomic distances quantified with our EXAFS data, viewed from along $b$ and $c$ axes.

bonding affect the geometry of the siderite crystals when $\mathrm{Ca}^{2+}$ replaces $\mathrm{Fe}^{2+}$ in the structure using the interatomic distances from our EXAFS data; and also the subsequent changes in the structure and morphology as evidenced by SEM. Furthermore, crystal packing for film development requires a modification to fit the new rounded morphology and piling up these crystals leaves gaps between the crystals (Figures $1 \mathrm{a}$ and S1). This in turn will affect the porosity and mechanical characteristics of the corrosion films conformed by these modified types of structures, and demonstrates how the introduction of another cation in the structure of siderite can change the characteristics of the material composing the corrosion film.

According to molecular dynamic simulations, the incorporation of $\mathrm{Fe}$ in the growth of calcite is initially an energetically very favorable (exothermic) process at the initial formation of calcite steps; however, subsequent incorporation of $\mathrm{Fe}$ becomes increasingly endothermic inhibiting further growth of the calcite crystals. ${ }^{22}$ The similarity in the spiral growth mode of siderite to the calcite system is not surprising but to our understanding this is the first time that the experimental data demonstrate the spiral growth of siderite in kink steps. In this growth mode, the birth of new faces along the $c$-axis intersects at obtuse and acute angles resulting in the inequivalent kink site along step edges, and it has been demonstrated that this inequivalence plays an important role in the incorporation of ions. ${ }^{21}$ Furthermore, spiral growth occurs around dislocation defects in steps that coil to form a spiral pyramid. ${ }^{23}$ In our iron calcium carbonate system, $\mathrm{Ca}^{2+}$ has a bigger ionic radius compared to $\mathrm{Fe}^{2+}$ and the incorporation of $\mathrm{Ca}^{2+}$ could be limited to obtuse steps to fit the bigger ion; however, the incorporation of $\mathrm{Ca}$ in the siderite structure inhibits its normal growth as observed in our SEM observations, and also demonstrated in the calcite system. ${ }^{25,26}$

Focusing on testing the behavior of a $\mathrm{Fe}_{0.66} \mathrm{Ca}_{0.33} \mathrm{CO}_{3}$ corrosion film, we performed flow experiments as described in the Methods section (i.e., $\mathrm{pH} 3.6$ and 7.0, flow velocity of 1 $\mathrm{m} / \mathrm{s}$ of $1 \% \mathrm{NaCl}$ solution at $80{ }^{\circ} \mathrm{C}$ for $24 \mathrm{~h}$ ) using the same conditions as previously reported for $\mathrm{FeCO}_{3}$ films. ${ }^{4}$ Initial observations evidenced the severe effect of low $\mathrm{pH}$ (3.6) and flow on the dissolution of the $\mathrm{Fe}_{0.66} \mathrm{Ca}_{0.33} \mathrm{CO}_{3}$ crystals provoking substantial breakage and leaving behind a porous material (Figure 6a,b). The damage is more severe than films

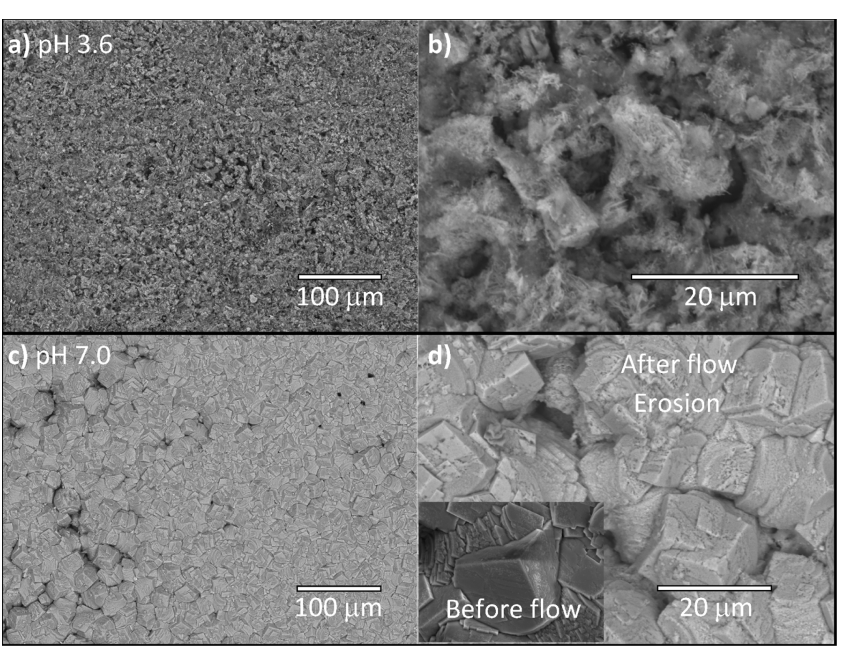

Figure 6. SEM images of the $\mathrm{Fe}_{0.66} \mathrm{Ca}_{0.33} \mathrm{CO}_{3}$ films after $24 \mathrm{~h}$ flow (1 $\mathrm{m} / \mathrm{s}$ ) at $80{ }^{\circ} \mathrm{C}$ using $1 \% \mathrm{NaCl}$ brine solution; (a,b) at $\mathrm{pH} 3.6$ evidencing the substantial damage on the film and showing the remains of the crystals; (c,d) at pH 7.0 still showing the crystals but visually eroded and more porous.

consisting of pure $\mathrm{FeCO}_{3}$ in experiments performed under the same conditions. ${ }^{4}$ This points out that the incorporation of $\mathrm{Ca}^{2+}$ in the structure of $\mathrm{FeCO}_{3}$ increases the dissolution of the iron calcium carbonate crystals in comparison to the film composed of pure siderite. The situation is more favorable for the $\mathrm{Fe}_{0.66} \mathrm{Ca}_{0.33} \mathrm{CO}_{3}$ crystals at $\mathrm{pH} 7.0$ as their morphology is still visible but they show signs of erosion and higher porosity expressed as rougher faces and deteriorated materials along the steps (Figure 6c,d). In addition, substantial dissolution of the $\mathrm{Fe}_{0.66} \mathrm{Ca}_{0.33} \mathrm{CO}_{3}$ film at low $\mathrm{pH}$ led to the transformation of $65 \%$ of $\mathrm{FeCO}_{3}$ from the top surface $(\sim 10 \mathrm{~nm})$ to $\mathrm{Fe}_{2} \mathrm{O}_{3}$, indicating higher chemical transformation than $\mathrm{FeCO}_{3}$ films; in which under the same experimental conditions, $88 \%$ of $\mathrm{FeCO}_{3}$ was preserved (Figure $7 \mathrm{~b}$ ). ${ }^{4}$ At neutral $\mathrm{pH}, \mathrm{Fe}^{0}$ from the steel was detected probably from the gaps between the crystals but nevertheless showing that the film is not protecting the steel (Figure 7c).

Surprisingly, the incorporation of $\mathrm{Ca}^{2+}$ in $\mathrm{FeCO}_{3}$ films is reversible as this element was not detected in $\mathrm{X}$-ray photoelectron spectroscopy (XPS) analyses after flow experiments under both $\mathrm{pH}$ conditions (Figure $7 \mathrm{~d}-\mathrm{f}$ ). This was further confirmed through energy-dispersive X-ray (EDX) mapping as the direct correlations found between $\mathrm{O}$ and $\mathrm{Ca}$ in $\mathrm{Fe}_{0.66} \mathrm{Ca}_{0.33} \mathrm{CO}_{3}$ films prior flow experiments were not found 

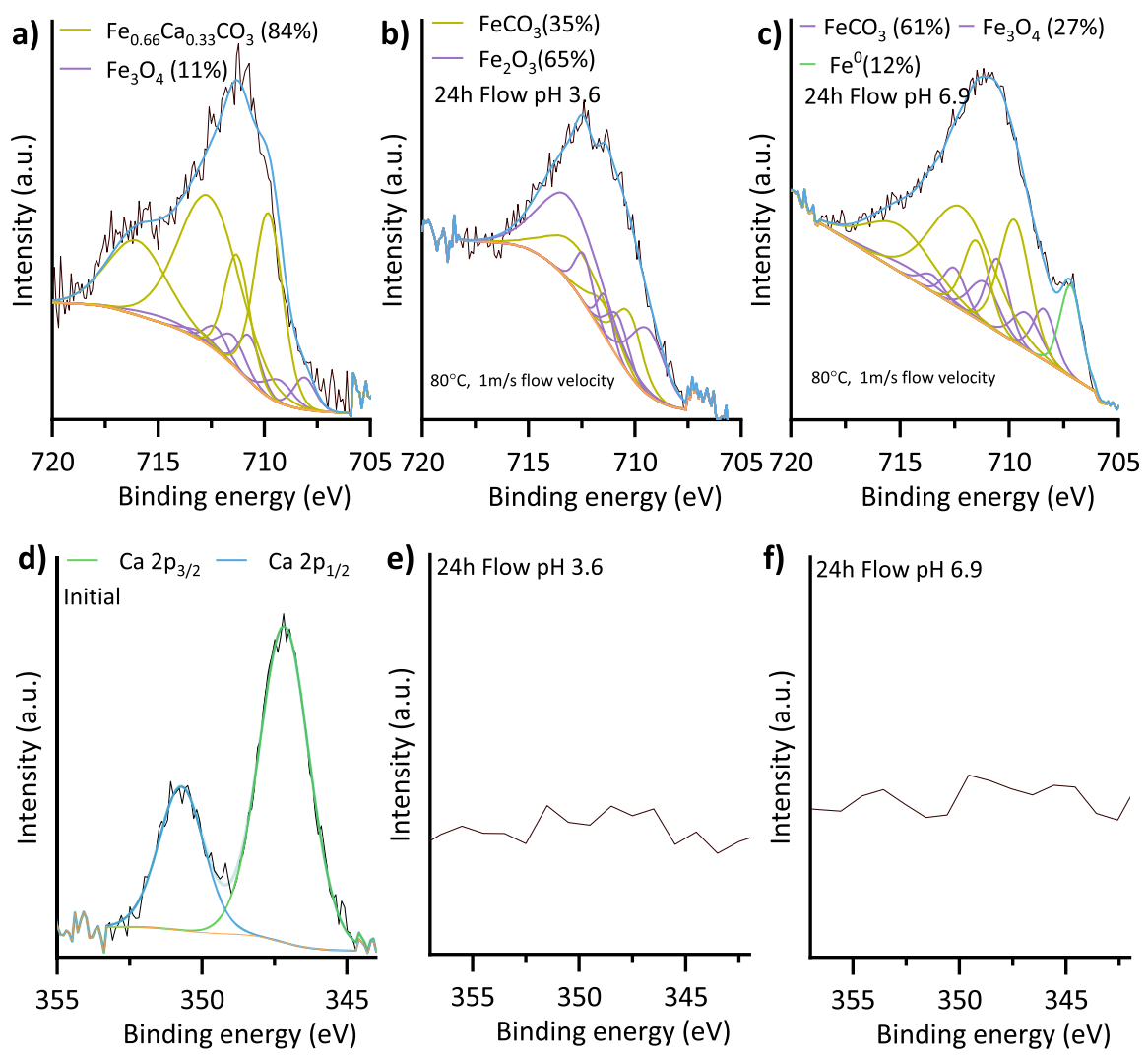

Figure 7. Fe 2 $\mathrm{p}_{3 / 2}$ XPS spectra collected from the surface of the $\mathrm{Fe}_{0.66} \mathrm{Ca}_{0.33} \mathrm{CO}_{3}$ corrosion film (a) as-formed; (b) at $\mathrm{pH} 3.6$; (c) at $\mathrm{pH} 7.0$; (d-f) and corresponding $\mathrm{Ca} 2 \mathrm{p}$ XPS spectra of these $\mathrm{Fe}_{0.66} \mathrm{Ca}_{0.33} \mathrm{CO}_{3}$ films.

afterward, indicating that both elements were initially part of the crystals but $\mathrm{Ca}$ was not present after flow, at least in detectable concentrations (Figure S2).

Moreover, the interatomic distances in the structure of the $\mathrm{Fe}_{0.66} \mathrm{Ca}_{0.33} \mathrm{CO}_{3}$ crystals after flow experiments were different to those in the initial $\mathrm{Fe}_{0.66} \mathrm{Ca}_{0.33} \mathrm{CO}_{3}$ crystals but closer to the interatomic distances in $\mathrm{FeCO}_{3}$ (Table S1). We were able to quantify them through the fit of the EXAFS data from a $\mathrm{Fe}_{0.66} \mathrm{Ca}_{0.33} \mathrm{CO}_{3}$ film after a flow experiment at $\mathrm{pH}$ 7.0. The fit was achieved by finding $S_{0}{ }^{2}$ to 0.90 for the first path and fixing it for the other three paths included. $\Delta E_{0}$ was $1.89 \pm 1.52$. Interatomic distances were consistent to the siderite model without the need of including $\mathrm{Ca}$ into the structure $\mathrm{Fe}-\mathrm{O}_{1}=$ $2.08 \AA, \mathrm{Fe}-\mathrm{C}_{1} \AA=2.94 \AA, \mathrm{Fe}-\mathrm{O}_{2}=3.20 \AA$, and $\mathrm{Fe}-\mathrm{Fe}_{1}=$ $3.65 \AA$ as the lixiviation of $\mathrm{Ca}^{2+}$ from the $\mathrm{Fe}_{0.66} \mathrm{Ca}_{0.33} \mathrm{CO}_{3}$ structure was also confirmed through $\mathrm{XRD}$ analyses (Figure $2 a, c)$.

\section{CONCLUSIONS}

Overall, our results indicate that $\mathrm{Ca}^{2+}$ readily incorporates into the siderite structure under static conditions to form an iron calcium carbonate product, that in our case consisted of $\mathrm{Fe}_{0.66} \mathrm{Ca}_{0.33} \mathrm{CO}_{3}$. The growth of the as-formed carbonate, a crystalline matrix of siderite with $\mathrm{Ca}^{2+}$ incorporated into the structure, occurs in steps and spiral dislocations following a similar growth mode to the described for the calcite system; however, the incorporation of $\mathrm{Ca}^{2+}$ inhibits the completion of spiral segments in the normal growth process of siderite. As a result, a new modified structure of the carbonate $\left(\mathrm{Fe}_{x} \mathrm{Ca}_{y} \mathrm{CO}_{3}\right)$ is formed with larger steps along the $c$-axis to allocate the bigger $\mathrm{Ca}^{2+}$ ions, expanding in turn the geometry and modifying the interatomic distances. As a consequence, a rounded type of the siderite crystal morphology is developed leading to the formation of a nonuniform corrosion film with different properties to $\mathrm{FeCO}_{3}$ causing adverse effects for the preservation of steel; (1) inefficient packing of the modified crystal morphology promotes localized corrosion; (2) the open structure of the formed $\mathrm{Fe}_{x} \mathrm{Ca}_{y} \mathrm{CO}_{3}$ along the $c$-axis allows the fast hydration of $\mathrm{Ca}^{2+}$ into the solution increasing the solubility of the film and exposing the steel to the fluids; and (3) these two effects weaken the mechanical properties of the corrosion films.

\section{METHODS}

Growth of corrosion products on X65 C-steel cylinders $(10 \mathrm{~mm} \varnothing$ and $6.25 \mathrm{~mm}$ thickness) was performed in an autoclave reactor. First, the specimens were wet ground using silicon carbide $(\mathrm{SiC})$ grit paper sizes of 120,320 , and 600 , then rinsed with deionized water and acetone and finally dried with air. $\mathrm{A} \mathrm{CO}_{2}$-saturated brine solution composed of $1 \% \mathrm{NaCl}$ and $220 \mathrm{mg} / \mathrm{L} \mathrm{Ca}$ was placed in the autoclave and the $\mathrm{pH}$ was adjusted to 7.0 at $80{ }^{\circ} \mathrm{C}$ using $\mathrm{NaHCO}_{3}$. Corrosion films were grown at $80^{\circ} \mathrm{C}$ under a total pressure $\mathrm{CO}_{2}$ of 30 bar for 72 h. Corrosion films without the presence of $\mathrm{Ca}$ in the brine were also produced using the same conditions in the absence of $220 \mathrm{mg} / \mathrm{L} \mathrm{Ca}$.

Flow experiments were conducted in an airtight experimental rig built to transfer a brine solution in a closed loop between a glass reactor (fitted with a $\mathrm{pH}$ electrode and a condenser) and a flow cell described in Matamoros-Veloza et al. 2020. ${ }^{4}$ A $24 \mathrm{~h} \mathrm{CO}_{2}$ saturated brine solution of $1 \% \mathrm{NaCl}$ at $80{ }^{\circ} \mathrm{C}$ was circulated with a flow velocity of $1 \mathrm{~m} / \mathrm{s}$ using a Micropump Series GJ-N25. The C-steel specimen with previously formed corrosion film was inserted in the flow-cell just before starting the experiment and the rig was deaerated for further 15 min. Dissolved oxygen concentration was measured using a DO probe (Intellical LDO101) and only when readings were below $50 \mathrm{ppb}$, the 
experiment was started. Experiments were performed at $\mathrm{pH} 3.6$ and $\mathrm{pH} 7.0$ (adjusted with $\mathrm{NaHCO}_{3}$ ) for $24 \mathrm{~h}$. We monitored $\mathrm{pH}$ using a Mettler Toledo $\mathrm{S} 213 \mathrm{pH} /$ conductivity meter. We used $\mathrm{NaCl}$ (Fluka/ Honeywell CAS 7647-14-5 99\%), $\mathrm{NaHCO}_{3}$ (Alfa Aesar 99\% CAS 144-55-8), and $\mathrm{CaCl}_{2} \cdot 2 \mathrm{H}_{2} \mathrm{O}$ (VWR CAS 10035-04-08 99.5\%). Specimens were carefully transferred for experiments and analyses (i.e., autoclave, flow cell rig, and instruments for analyses), and they were always kept dried in vacuum sealed bags in a vacuum desiccator.

XRD analyses were conducted directly on rinsed and air-dried specimens mounted onto a holder and scanned from 15 to $80^{\circ} 2 \theta$ at $1.55^{\circ} / \mathrm{min}$ using a Bruker D8 X-ray diffractometer. Our diffraction data were compared to that of the structures of siderite, calcite, and $\alpha$ $\mathrm{Fe}^{30-32}$ References of the International Centre for Diffraction Data (ICDD) were used for siderite (ICDD 8-0133), calcite (ICDD 50586), and $\alpha$-Fe (ICDD 6-0696). SEM imaging was performed on specimens fixed onto stubs using high-purity double-sided conductive adhesive carbon tabs and mounted on the sample stage of the instrument (TM3030Plus microscope), which was operated at $15 \mathrm{kV}$.

XPS analyses were performed on the surface of the specimens (300 $\mu \mathrm{m} \times 300 \mu \mathrm{m}, \sim 10 \mathrm{~nm}$ depth) using an EnviroESCA instrument equipped with a monochromatic $\mathrm{Al} \mathrm{K \alpha}(1.487 \mathrm{keV}) \mathrm{X}$-ray source. For the analyses, the specimens were mounted onto stubs using highpurity double-sided conductive adhesive carbon tabs. The instrument was operated at $3.3 \mathrm{mbar}$ and ${ }^{48} \mathrm{Ar}$ gas was used for charge compensation. First, we collected survey spectra between 15 and 1500 $\mathrm{eV}$ with a pass energy of $100 \mathrm{eV}$; then high-resolution spectra were collected at the binding energies of $\mathrm{Fe}(700-740 \mathrm{eV}), \mathrm{Ca}(340-355$ $\mathrm{eV}), \mathrm{O}(525-545 \mathrm{eV})$, and $\mathrm{C}(280-295 \mathrm{eV})$, with a pass energy of $20 \mathrm{eV}$ and a step size of $0.1 \mathrm{eV}$. Binding energy calibration was performed at $285 \mathrm{eV}$ using the carbon $1 \mathrm{~s}$ peak. For XPS data analyses, CasaXPS software was used following the procedure described in Biesinger et al. $2011 .{ }^{33} \mathrm{Fe} 2 \mathrm{p}_{3 / 2}$ high-resolution spectra were fitted using multiple peaks and Shirley background subtraction.

In order to obtain information about the local chemistry of $\mathrm{Fe}$ in the corrosion films and to quantify any changes in the structure when $\mathrm{Ca}$ is present, Fe K-edge X-ray absorption (XAS) analyses were performed at Diamond Light Source on I18 beamline. For the analyses, a $\mathrm{Si}(111)$ monochromator with an energy resolution $(\Delta E /$ $E)$ of $1.4 \times 10^{-4}$ was calibrated using a Fe-foil at $7111.99 \mathrm{eV}$. We analyzed $\mathrm{Fe}_{0.66} \mathrm{Ca}_{0.33} \mathrm{CO}_{3}$ and $\mathrm{FeCO}_{3}$ corrosion films (initial and after flow) at pH 7.0 and with a flow velocity of $1 \mathrm{~m} / \mathrm{s}$. Immediately after the experiments, the films were removed from the flow and prepared as focused ion beam (FIB) lamellae ( 500-1000 nm thick). For this, we embedded the specimens in resin and fast polished them using 600 $\mathrm{SiC}$ grit paper to expose the cross section and dried with air.

To prepare the lamellae, a coat of $20 \mu \mathrm{m}$ of Ir was applied using an Agar Scientific sputter coater to reduce the charge effects and transferred into a FIB FEI Helios G4 CX Dual Beam microscope. A 1 $\mu \mathrm{m}$ thick Pt layer was applied on an area of $20 \mu \mathrm{m}$ length and a $2 \mu \mathrm{m}$ width using a $\mathrm{Ga}^{+}$Ion beam, then a beam current of $21 \mathrm{nA}$ was applied to remove the material from either side of the lamella, which was subsequently thinned using progressively smaller beam current ( 9 $\mathrm{nA}$ to $40 \mathrm{pA}$ ) until achieving the desired thickness. This preparation process yielded lamellae with areas between 280 and $800 \mu \mathrm{m}^{2}$, which were kept in vacuum until analysis.

For the acquisition of the $\mu$-XANES data for mapping, the lamellae were placed at $45^{\circ}$ to the incident beam and the energy-dispersive silicon drift 4-element Vortex ME-4 detector with a Cube preamplifier was positioned normal to the beam direction. Fe foil was used to calibrate the monochromator at $7112 \mathrm{eV} .150 \mathrm{Fe}$ fluorescence maps were collected at discrete energies between 7000 and $7250 \mathrm{eV}$ in the raster mode with a pixel size of $2 \mu \mathrm{m} \times 2 \mu \mathrm{m}$ using $0.1 \mathrm{~s}$ per pixel. Mn fluorescence maps were also acquired to identify the areas corresponding to the steel. It was necessary to use an aluminum filter of $0.25 \mathrm{~mm}$ to attenuate the incident X-ray beam and to ensure the linear response of the detector. In addition, XANES spectra were collected from $\mathrm{FeO}, \mathrm{Fe}_{2} \mathrm{O}_{3}, \mathrm{Fe}_{3} \mathrm{O}_{4}$, and $\mathrm{FeCO}_{3}$ as references for linear combination fitting (LCF). In addition, $\mu$-XANES and $\mu$-EXAFS spectra of the $\mathrm{Fe}_{0.66} \mathrm{Ca}_{0.33} \mathrm{CO}_{3}$ films were collected between 7000 and
$7400 \mathrm{eV}$ while spectra of a $\mathrm{FeCO}_{3}$ film were collected between 6911 and $7580 \mathrm{eV}$. A step size of $\sim 0.5 \mathrm{eV}$ was used for the measurements.

To produce the XANES maps, a python script was used to stack and convert the fluorescence maps to a single file, they were aligned and analyzed using principal component analysis (PCA) and then cluster analysis in Mantis. ${ }^{34}$ First, the number of spectral components from PCA was determined and then it was used in iterations to find the number of clusters until reaching a local minimum with no further changes on the map. ${ }^{35}$ Individual spectra were also obtained from regions of interest (ROI) from the maps to find spectra representative of the films.

The raw XANES data were aligned, averaged prior to normalization, and the background was subtracted using Athena software. ${ }^{36}$ The spectra were analyzed by comparing the $\mathrm{FeCO}_{3}$ and $\mathrm{Fe}_{0.66} \mathrm{Ca}_{0.33} \mathrm{CO}_{3}$ spectra among themselves and with references. We compared the normalized Fe K-edge XANES spectra of the clusters and ROI to the spectra of the Fe references both experimental and from databases. ${ }^{37,38}$ We performed LCF analysis between $20 \mathrm{eV}$ below and $30 \mathrm{eV}$ above the edge.

The EXAFS region from the spectra was analyzed with Artemis. ${ }^{36}$ The EXAFS data were fitted to a theoretical model generated using the siderite structure in FEFF6 and ATOMS. ${ }^{36}$ Four single-scattering paths were considered in the fit, $\mathrm{Fe}-\mathrm{O}_{1}$ (first shell) and $\mathrm{Fe}-\mathrm{C}, \mathrm{Fe}-$ $\mathrm{O}_{2}$ and $\mathrm{Fe}-\mathrm{Fe}_{1}$ (second shell). We used a shell by shell-fitting approach, finding the amplitude parameter $\left(S_{0}{ }^{2}\right)$ for the first shell to be 0.89 that was later used as a fixed value for the four paths. Coordination numbers $(\mathrm{N})$ were used as generated from the theoretical model. The energy shift $\left(\Delta E_{0}\right)$ was floated as a fitting parameter and it was constrained to be the same for the four paths. The disorder parameter in the distribution of interatomic distances $\left(\sigma^{2}\right)$ was also allowed to float in the fits. The quality of the fits was assessed against the reduced $\chi^{2}$ and the $R$-factor. ${ }^{39}$ Interatomic distance $(R)$, disorder $\left(\sigma^{2}\right)$, and inner potential corrections $(\Delta E)$ were extracted from the fits. It is worth noting that despite fitting all our data within a short $k$-space range, the number of independent points used for the fitting was twice the number of variables following the Stern's rule. ${ }^{40}$ All fits were achieved using least squares multiple $k$ weight fitting. Further details of the fitting process for $\mathrm{Fe}_{0.66} \mathrm{Ca}_{0.33} \mathrm{CO}_{3}$ before and after flow are presented in Supporting Information.

\section{ASSOCIATED CONTENT}

\section{s) Supporting Information}

The Supporting Information is available free of charge at https://pubs.acs.org/doi/10.1021/acsami.0c14513.

SEM images of the as-formed $\mathrm{Fe}_{0.66} \mathrm{Ca}_{0.33} \mathrm{CO}_{3}$ corrosion products on $\mathrm{C}$-steel; $\mathrm{EDX}$ maps of $\mathrm{O}$ and $\mathrm{Ca}$ of $\mathrm{Fe}_{0.66} \mathrm{Ca}_{0.33} \mathrm{CO}_{3}$ corrosion products before and after flow experiments; $\mathrm{O} 1 \mathrm{~s}$ XPS spectra collected from $\mathrm{Fe}_{0.66} \mathrm{Ca}_{0.33} \mathrm{CO}_{3}$ (initial and after flow) films; further details of the fitting process of $\mathrm{Fe}_{0.66} \mathrm{Ca}_{0.33} \mathrm{CO}_{3}$ EXAFS data; EXAFS fitting parameters derived from fitting the spectra of $\mathrm{Fe}_{0.66} \mathrm{Ca}_{0.33} \mathrm{CO}_{3}$ (initial and after flow) and $\mathrm{FeCO}_{3}$ films; and $\mathrm{Fe} 2 \mathrm{p}_{3 / 2}, \mathrm{Ca} 2 \mathrm{p}_{3 / 2}$, and $\mathrm{O} 1 \mathrm{~s}$ spectral fitting parameters (PDF)

\section{AUTHOR INFORMATION}

\section{Corresponding Author}

Adriana Matamoros-Veloza - School of Mechanical Engineering, University of Leeds, Leeds LS2 9JT, U.K.; (1) orcid.org/0000-0002-3870-9141; Email: A.MatamorosVeloza@leeds.ac.uk

\author{
Authors \\ Richard Barker - School of Mechanical Engineering, University \\ of Leeds, Leeds LS2 9JT, U.K.
}


Silvia Vargas - BP America, Inc., Houston, Texas 77079, United States

Anne Neville - School of Mechanical Engineering, University of Leeds, Leeds LS2 9JT, U.K.

Complete contact information is available at: https://pubs.acs.org/10.1021/acsami.0c14513

\section{Notes}

The authors declare no competing financial interest.

\section{ACKNOWLEDGMENTS}

The authors would like to acknowledge the funding and technical support from BP through the BP International Center for Advanced Materials (BP-ICAM), which made this research possible. This work was also partly funded by the EPSRC through the Prosperity partnership grant (EP/ R00496X/1). The authors also thank the funding provided by Diamond Light Source through the allocated beamtime on I18 (SP21717-1) and the invaluable support from Konstantin Ignatyev and Kalotina Geraki on spectroscopy data collection. Many thanks to the technical support from the Institute of functional Surfaces at Leeds in addition to Dr Yong Hua for his assistance with autoclave handling. Also, thanks to Mariana Costa Folena and Dlshad Shaikhah for their help with synchrotron measurements.

\section{REFERENCES}

(1) World-Steel-Association. World Steel in Figures 2019. https:// www.worldsteel.org/media-centre/press-releases/2019/world-steelin-figures-2019.html (accessed on 14/07/2020).

(2) Jacobson, G. A. NACE International's IMPACT Study Breaks New Ground in Corrosion Management Research and Practice. Bridge. 2016, 46, 30.

(3) Barker, R.; Hua, Y.; Neville, A. Internal Corrosion of Carbon Steel Pipelines for Dense-Phase $\mathrm{CO}_{2}$ Transport in Carbon Capture and Storage (CCS) - A Review. Int. Mater. Rev. 2017, 62, 1-31.

(4) Matamoros-Veloza, A.; Barker, R.; Vargas, S.; Neville, A. Mechanistic Insights of Dissolution and Mechanical Breakdown of FeCO3 Corrosion Films. 2009, arXiv:2009.11711. http://arxiv.org/ abs/2009.11711.

(5) Chan, E. W. L. Magnetite and its Galvanic Effect on the Corrosion of Carbon Steel under Carbon Dioxide Environments; Curtin University, 2011.

(6) Ding, C.; Gao, K.-w.; Chen, C.-f. Effect of $\mathrm{Ca}^{2+}$ on $\mathrm{CO}_{2}$ Corrosion Properties of X65 Pipeline Steel. Int. J. Miner., Metall. Mater. 2009, 16, 661-666.

(7) Esmaeely, S. N.; Choi, Y.-S.; Young, D.; Nešić, S. Effect of Calcium on the Formation and Protectiveness of Iron Carbonate Layer in $\mathrm{CO}_{2}$. Corrosion 2013, 69, 912-920.

(8) Gao, K.; Yu, F.; Pang, X.; Zhang, G.; Qiao, L.; Chu, W.; Lu, M. Mechanical Properties of $\mathrm{CO}_{2}$ Corrosion Product Scales and their Relationship to Corrosion Rates. Corros. Sci. 2008, 50, 2796-2803.

(9) Zhao, G.; Li, J.; Hao, S.; U X, L. H. Effect of $\mathrm{Ca}^{2+}$ and $\mathrm{Mg}^{2+}$ on $\mathrm{CO}_{2}$ Corrosion Behavior of Tube Steel. J. Iron Steel Res. Int. 2005, 12, $38-42$.

(10) Hua, Y.; Shamsa, A.; Barker, R.; Neville, A. Protectiveness, Morphology and Composition of Corrosion Products Formed on Carbon Steel in the Presence of $\mathrm{Cl}^{-}, \mathrm{Ca}^{2+}$ and $\mathrm{Mg}^{2+}$ in High Pressure $\mathrm{CO}_{2}$ Environments. Appl. Surf. Sci. 2018, 455, 667-682.

(11) Wang, B.; Xu, L.; Liu, G.; Lu, M. Corrosion Behavior and Mechanism of ${ }^{3} \mathrm{Cr}$ Steel in $\mathrm{CO}_{2}$ Environment with Various $\mathrm{Ca}^{2+}$ Concentration. Corros. Sci. 2018, 136, 210-220.

(12) Tavares, L. M.; Costa, E. M. d.; Andrade, J. J. d. O.; Hubler, R.; Huet, B. Effect of Calcium Carbonate on Low Carbon Steel Corrosion Behavior in Saline $\mathrm{CO}_{2}$ High Pressure Environments. Appl. Surf. Sci. 2015, 359, 143-152.
(13) Shamsa, A.; Barker, R.; Hua, Y.; Barmatov, E.; Hughes, T. L.; Neville, A. The Role of $\mathrm{Ca}^{2+}$ Ions on $\mathrm{Ca} / \mathrm{Fe}$ Carbonate Products on X65 Carbon Steel in $\mathrm{CO}_{2}$ Corrosion Environments at 80 and $150^{\circ} \mathrm{C}$. Corros. Sci. 2019, 156, 58-70.

(14) Alsaiari, H. A.; Kan, A.; Tomson, M. Effect of Calcium and Iron (II) Ions on the Precipitation of Calcium Carbonate and Ferrous Carbonate. SPE J. 2010, 15, 294-300.

(15) Jiang, X.; Zheng, Y. G.; Qu, D. R.; Ke, W. Effect of Calcium Ions on Pitting Corrosion and Inhibition Performance in $\mathrm{CO}_{2}$ Corrosion of N80 steel. Corros. Sci. 2006, 48, 3091-3108.

(16) Jiang, X.; Nešíc, S.; Kinsella, B.; Brown, B.; Young, D. Electrochemical Investigation of the Role of $\mathrm{Cl}^{-}$on Localized Carbon Dioxide Corrosion Behavior of Mild Steel. Corrosion 2013, 69, 15-24.

(17) Joshi, G. R.; Cooper, K.; Zhong, X.; Cook, A. B.; Ahmad, E. A.; Harrison, N. M.; Engelberg, D. L.; Lindsay, R. Temporal Evolution of Sweet Oilfield Corrosion Scale: Phases, Morphologies, Habits, and Protection. Corros. Sci. 2018, 142, 110-118.

(18) Neugebauer, P.; Cardona, J.; Besenhard, M. O.; Peter, A.; Gruber-Woelfler, H.; Tachtatzis, C.; Cleary, A.; Andonovic, I.; Sefcik, J.; Khinast, J. G. Crystal Shape Modification via Cycles of Growth and Dissolution in a Tubular Crystallizer. Cryst. Growth Des. 2018, 18, 4403-4415.

(19) Milella, F.; Mazzotti, M. Estimation of the Growth and the Dissolution Kinetics of Ammonium Bicarbonate in Aqueous Ammonia Solutions from Batch Crystallization Experiments. Cryst. Growth Des. 2019, 19, 5907-5922.

(20) Teng, H. H.; Dove, P. M.; Orme, C. A.; De Yoreo, J. J. Thermodynamics of Calcite Growth: Baseline for Understanding Biomineral Formation. Science 1998, 282, 724-727.

(21) Larsen, K.; Bechgaard, K.; Stipp, S. L. S. The Effect of the $\mathrm{Ca}^{2+}$ to $\mathrm{CO}_{3}{ }^{2-}$ Activity Ratio on Spiral Growth at the Calcite $\{10 \overline{1} 4\}$ Surface. Geochem. Cosmochim. Acta 2010, 74, 2099-2109.

(22) De Leeuw, N. H. Molecular Dynamics Simulations of the Growth Inhibiting Effect of $\mathrm{Fe}^{2+}, \mathrm{Mg}^{2+}, \mathrm{Cd}^{2+}$, and $\mathrm{Sr}^{2+}$ on Calcite Crystal Growth. J. Phys. Chem. B 2002, 106, 5241-5249.

(23) Larsen, K.; Bechgaard, K.; Stipp, S. L. S. Modelling Spiral Growth at Dislocations and Determination of Critical Step Lengths from Pyramid Geometries on Calcite $\{10 \overline{1} 4\}$ Surfaces. Geochem. Cosmochim. Acta 2010, 74, 558-567.

(24) Di Lorenzo, F.; Burgos-Cara, A.; Ruiz-Agudo, E.; Putnis, C. V.; Prieto, M. Effect of Ferrous Iron on the Nucleation and Growth of $\mathrm{CaCO}_{3}$ in Slightly Basic Aqueous Solutions. CrystEngComm 2017, 19, 447-460.

(25) De Yoreo, J. J.; Vekilov, P. G. Principles of Crystal Nucleation and Growth. Rev. Mineral. Geochem. 2003, 54, 57-93.

(26) Cabrera, N.; Vermilyea, D. A. The Growth of Crystals from Solution. Growth and Perfection of Crystals. Proceedings of an International Conference on Crystal Growth. Cooperstown; Wiley: New York, 1958; pp 393-407.

(27) Henderson, G. S.; De Groot, F. M. F.; Moulton, B. J. A. Geochemistry, X-ray Absorption Near-Edge Structure (XANES) Spectroscopy. Rev. Mineral. Geochem. 2014, 78, 75-138.

(28) Wilke, M.; Farges, F.; Petit, P.-E.; Brown, G. E.; Martin, F. Oxidation State and Coordination of Fe in Minerals: An Fe K-XANES Spectroscopic Study. Am. Mineral. 2001, 86, 714-730.

(29) Berry, A. J.; O’Neill, H. S. C.; Jayasuriya, K. D.; Campbell, S. J.; Foran, G. J. XANES Calibrations for the Oxidation State of Iron in a Silicate Glass. Am. Mineral. 2003, 88, 967-977.

(30) Effenberger, H.; Mereiter, K.; Zemann, J. Crystal Structure Refinements of Magnesite, Calcite, Rhodochrosite, Siderite, Smithonite, and Dolomite, with Discussion of Some Aspects of the Stereochemistry of Calcite Type Carbonates. Cryst. Mater. 1981, 156, 233.

(31) Owen, E. A.; Yates, E. L. XLI. Precision Measurements of Crystal Parameters. Lond. Edinb. Dubl. Phil. Mag. 1933, 15, 472-488.

(32) Swanson, H. E.; Fuyat, R. K. Standard X-ray Diffraction Patterns. J. Res. Natl. Bur. Stand. 1951, 46, 318.

(33) Biesinger, M. C.; Payne, B. P.; Grosvenor, A. P.; Lau, L. W. M.; Gerson, A. R.; Smart, R. S. C. Resolving Surface Chemical States in 
XPS Analysis of First Row Transition Metals, Oxides And Hydroxides: Cr, Mn, Fe, Co and Ni. Appl. Surf. Sci. 2011, 257, 2717-2730.

(34) Lerotic, M.; Mak, R.; Wirick, S.; Meirer, F.; Jacobsen, C. MANTiS: a Program for the Analysis of X-ray Spectromicroscopy Data. J. Synchrotron Radiat. 2014, 21, 1206-1212.

(35) Brinza, L.; Schofield, P. F.; Hodson, M. E.; Weller, S.; Ignatyev, K.; Geraki, K.; Quinn, P. D.; Mosselmans, J. F. W. Combining microXANES and microXRD Mapping to Analyse the Heterogeneity in Calcium Carbonate Granules Excreted by the Earthworm Lumbricus Terrestris. J. Synchrotron Radiat. 2014, 21, 235-241.

(36) Ravel, B.; Newville, M. ATHENA, ARTEMIS, HEPHAESTUS: Data Analysis for X-Ray Absorption Spectroscopy using IFEFFIT. J. Synchrotron Radiat. 2005, 12, 537-541.

(37) http://xraysweb.lbl.gov/uxas/Databases/Overview.htm (accessed on $08 / 06 / 2020)$.

(38) https://cars.uchicago.edu/xaslib/search/Fe (accessed on 08/ 06/2020).

(39) Binsted, N.; Hasnain, S. S. State-of-the-Art Analysis of Whole X-ray Absorption Spectra. J. Synchrotron Radiat. 1996, 3, 185-196.

(40) Stern, E. A. Number of Relevant Independent Points in X-RayAbsorption Fine-Structure Spectra. Phys. Rev. B Condens. Matter 1993, $48,9825$. 